\title{
Visible light switching of metallosupramolecular assemblies
}

\author{
Aaron D. W. Kennedy, ${ }^{\dagger}$ Ray G. DiNardi, ${ }^{\dagger}$ Lucy L. Fillbrook, William A. Donald and Jonathon E. \\ Beves*
}

School of Chemistry, UNSW Sydney, Sydney NSW 2052, Australia

Self-assembly, photochromic, photoswitchable, azobenzene, supramolecular

\begin{abstract}
A photoswitchable ligand and palladium(II) ions form a dynamic mixture of self-assembled metallosupramolecular structures. The photoswitching ligand is an ortho-fluoroazobenzene with appended pyridyl groups. The $E$-isomer is combined with palladium(II) salts affords a double-walled triangle with composition $\left[\mathrm{Pd}_{3} \mathrm{~L}_{6}\right]^{6+}$ and a distorted tetrahedron $\left[\mathrm{Pd}_{4} \mathrm{~L}_{8}\right]^{8+}(1: 2$ ratio at $298 \mathrm{~K})$. Irradiation with $410 \mathrm{~nm}$ light generates a photostationary state with $\sim 80 \%$ of the $E$-isomer of the ligand which results in the selective disassembly of the tetrahedron, the more thermodynamically stable structure, and the formation of the triangle, the kinetic product. The triangle is then slowly transformed back into the tetrahedron over 2 days at $333 \mathrm{~K}$. The $Z$-isomer of the ligand does not form any well-defined structures and has a thermal half-life of 25 days at $298 \mathrm{~K}$. This approach shows how a thermodynamically preferred self-assembled structure can be reversibly pumped to a kinetic trap by small perturbations of the isomer distribution using non-destructive visible light.
\end{abstract}

\section{INTRODUCTION}

The structure and function of self-assembled species, such as molecular cages, can be controlled using stimuliresponsive components. Different stimuli have been used to perturb metal-template supramolecular assemblies ${ }^{1}$ including light, ${ }^{2}$ guest molecules, ${ }^{3} \mathrm{pH}$ changes, ${ }^{4}$ competing ligand $s^{5}$ and changes to solvent. ${ }^{6}$ Light, especially the visible spectrum, ${ }^{7}$ is appealing due to its easy use, potential for highly specific targeting, and the high resolution of spatial and temporal application. ${ }^{8}$ Molecular photoswitches, ${ }^{9}$ can be isomerized reversibly by light, with each isomer having different geometries and electronic properties. These differences in properties have been used to control the properties of gels, ${ }^{10}$ polymers assemblies, ${ }^{11}$ or liquid crystals, ${ }^{12}$ and to perform functions including acting as light-activated receptors ${ }^{13}$ or pharmaceticals, ${ }^{14}$ or pumping systems away from thermodynamic equilibrium. ${ }^{15}$ The most studied photoswitches are those based on azobenzene, ${ }^{16}$ which can be isomerized between a stable $E$-isomer and a metastable $Z$-isomer. However, unsubstituted azobenzene requires potentially destructive UV light to form the meta-stable $Z$-isomer that has a thermal half-life at room temperature of only 2 days. Significant advances have been made in developing azobenzene-type molecules that operate effectively with visible light, ${ }^{9 c, 17}$ with one of the most successful modifications being the introduction of ortho-fluoro substituents (Figure 1a). ${ }^{18}$ These ortho-fluoroazobenzenes allow bidirectional visible-light switching with thermal half-lives that can exceed 2 years and have been incorporated into MOFs ${ }^{18 \mathrm{~g}}$ and discrete self-assembled structures, ${ }^{18 \mathrm{~h}}$ and have been used to control molecular folding ${ }^{18 f}$ or the function of enzymes. ${ }^{18 \mathrm{j}}$

Conceptually there are two approaches for combining photoswitches with discrete self-assembled structures: encapsulation or direct incorporation as part of the struc- ture. The first strategy involves binding the photoactive unit inside a cavity, such as encapsulating azobenzene type derivatives. ${ }^{19}$ Encapsulation a photoswitch can also restrict switching or perturb the balance of isomers. ${ }^{19 b, 20}$

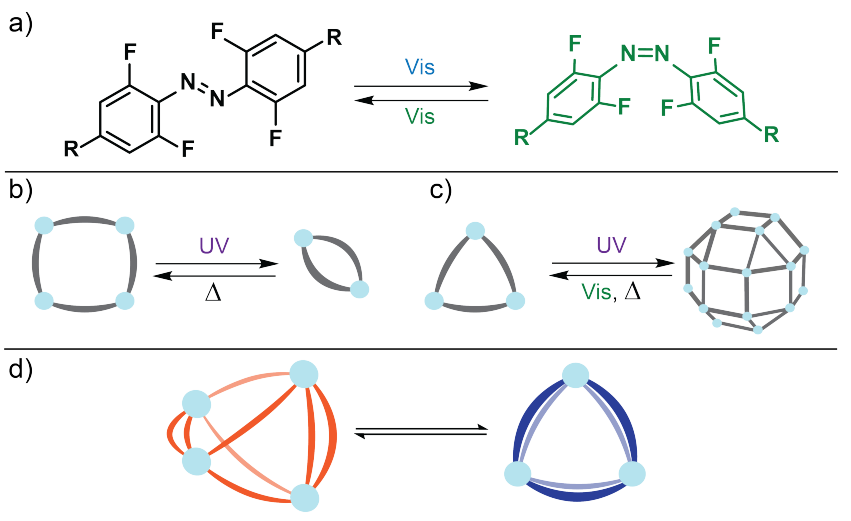

Figure 1. a) ortho-Fluoroazobenzene switching induced by visible light. We will define the parent compound has $R=H . b$ ) and c) Cartoon representation of previous examples $27 b, 29$ of light induced topology changes in metal-based supramolecular structures and d) this work, showing light induced topology changes with both structures comprising the same ligand isomerization state.

Using photoswitches as structural components of selfassembled structures has proven more difficult. Although there are many examples of large photoswitchable assemblies, ${ }^{21}$ such as micelles, vesicles or liquid crystals ${ }^{12}$ formed with polymers, ${ }^{11}$ there are relatively few examples of photoswitches being self-assembled into well-defined, discrete structures. In a key example, pyridine-based ligands and palladium(II) were self-assembled into a $\left[\mathrm{Pd}_{12} \mathrm{~L}_{24}\right]^{24+}$ molecular sphere with endohedral azobenzene groups ${ }^{2 a}$ which could be switched with UV to increase the hydrophilicity of the sphere's cavity. Some other examples of 
pyridyl-functionalized switches include $\left[\mathrm{M}_{2} \mathrm{~L}_{4}\right]^{4+}$ cages formed with stiff-stilbenes and palladium(II),22 chiral $\left[\mathrm{M}_{6} \mathrm{~L}_{3}\right]^{6+}$ metallocycles formed from dithienylethene (DTEs) ${ }^{23}$ and platinum(II), ${ }^{24}$ and related ligands reacted with iron(II/III) to form $\left[\mathrm{Fe}_{2} \mathrm{~L}_{3}\right]^{\mathrm{n}+}$ helicates. ${ }^{25}$

The first example of a molecular cage with functioning azobenzene-type photoswitches as linkers used cyclotriguaiacylene units with three appended pyridyl-azo-phenyl photoswitches and iridium(III) complexes to form $\left[\mathrm{Ir}_{3} \mathrm{~L}_{2}\right]^{3+}$ cages. ${ }^{26}$ The flexible linkers allowed photoswitching to occur without disrupting the cage topology. The most wellstudied photoswitchable cages are based on pyridylfunctionalized DTE photoswitches assembled with palladium(II) ions reported by the Clever group. ${ }^{27}$ The difference in geometries has been exploited for selective guest uptake, ${ }^{27 a, 27 d, 27 e}$ and control over macromolecular properties when incorporated into gels. ${ }^{28}$

Photoswitching units can also modulate the topology of metallosupramolecular structures; however, this usually leads to the assembly of new non-discrete structures. ${ }^{30}$ There are few reported examples of modulation between discrete metallosupramolecular structures, with some key examples represented in Figure 1b,c. ${ }^{27 b, 29}$ One example used azobenzene or stilbene based ligands to form $\left[\mathrm{M}_{2} \mathrm{M}_{2}{ }_{2} \mathrm{~L}_{4}\right]^{8+}\left(\mathrm{M}=\mathrm{Pd}, \mathrm{M}^{\prime}=\mathrm{Pd}\right.$ or $\left.\mathrm{Re}\right)$ macrocycles where UV irradiation isomerize the azo unit to contract the macrocycle to the smaller $\left[\mathrm{M}_{2} \mathrm{~L}_{2}\right]^{4+}$ species. ${ }^{29,31}$ Other examples use DTE-based ligands.27b,27e For one system, the open and closed isomers give rise to a double-walled triangle (as the major component) and a cuboctahedral sphere, respectively. ${ }^{27 b}$ These species can be interconverted using UV and green light, giving reversible control over the structure by external stimuli although the conversion was relatively slow, with a full cycle taking over 3 days. A more recent example was able to eject one ligand from a $\mathrm{Pd}_{2} \mathrm{~L}_{4}$ cage upon irradiation. ${ }^{27 e}$ Despite these examples, there are no reports of metallosupramolecular structures which can be reversibly rearranged using visible light only.

Herein we report a system of two discrete metallosupramolecular assemblies, formed from an orthofluoroazobenzene ligand (Figure 1d). The system can be driven out-of-equilibrium with visible light due to the different kinetic labilities of the structures. To the best of our knowledge this is one of the only examples of light-induced topology changes and the first example of all-visible light switching between discrete structures.

\section{RESULTS AND DISCUSSION}

We synthesized substituted ortho-fluoroazobenzenes in moderate yield over three steps from commercially available 4-bromo-2,6-difluoroaniline (see SI-1,2 for details). ${ }^{32}$ Compound 1 was obtained in 65\% yield using a methodology previously used to generate unsymmetrical azobenzene derivatives, ${ }^{18 a, 18 b, 33 a, 33 b}$ Boronic ester substituted ortho-fluoroazobenzene 2 has been previously reported, ${ }^{18 c}$ but use of microwave heating allowed us to reduce the reaction time to 15 minutes with a trivial work-up that excluded chromatography. Suzuki coupling gave the photoswitchable ligand 3 (53\% yield) and the control compound, phenyl derivative 4 (20\% yield). The second coupling reaction did not always reach completion despite the
Scheme 1. Synthesis of pyridyl-appended ortho-fluoroazobenzene 3 .

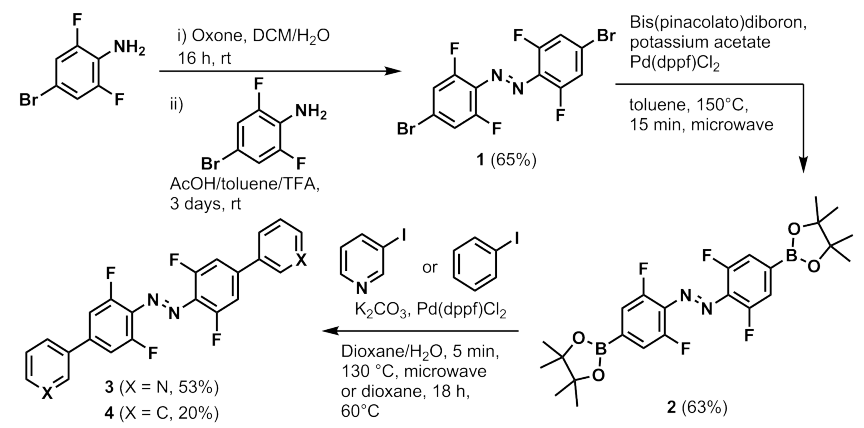

a) i) Oxone, $\mathrm{DCM} / \mathrm{H}_{2} \mathrm{O}(1: 4), 16 \mathrm{~h}, \mathrm{RT}$. ii) 4-Bromo-2,6difluoroaniline, AcOH/toluene/TFA (6:6:1), 72 h, RT. b) $\mathrm{Pd}(\mathrm{dpp}) \mathrm{Cl}_{2}$, (BPin)2, KOAc, toluene, $150{ }^{\circ} \mathrm{C}(\mu \mathrm{W}), 15$ min. c) 3-Iodopyridine, $\mathrm{Pd}(\mathrm{dppf}) \mathrm{Cl}_{2}, \mathrm{~K}_{2} \mathrm{CO}_{3}, 1$,4-dioxane $/ \mathrm{H}_{2} \mathrm{O}$ (7:1), $130{ }^{\circ} \mathrm{C}(\mu \mathrm{W}), 5 \mathrm{~min}$; or iodobenzene, $\mathrm{Pd}(\mathrm{dppf}) \mathrm{Cl}_{2}, \mathrm{~K}_{2} \mathrm{CO}_{3}, 1,4-$ dioxane, $60{ }^{\circ} \mathrm{C}(\mu \mathrm{W}), 18 \mathrm{~h}$. See SI- 2 for details.

arylhalide being in excess, with the mono-substituted product being identified and characterized (see SI-2.4, SI16 for details). This suggests the second coupling reaction is considerably more difficult than the first. The compounds were isolated as mixtures of the thermodynamically favored $E$-isomer and the metastable $Z$-isomer. Heating a solution of 3 in DMSO- $d_{6}$ generated the pure $E-\mathbf{3}$ isomer as observed by ${ }^{1} \mathrm{H}$ and ${ }^{19} \mathrm{~F}$ NMR spectra (Figure $\left.2 \mathrm{~b}\right) .{ }^{34}$

The UV-vis absorption of photoswitchable ligand $E-3$ (Figure 2c) extends into the visible, with a visible absorption maximum at $466 \mathrm{~nm}$ assigned as the $n-\pi^{*}$ band and a band at $356 \mathrm{~nm}$ assigned to the $\pi-\pi^{*}$ transition (in DMSO at $298 \mathrm{~K}$ ). Both transitions are red-shifted relative to the parent ortho-fluoroazobenzene, which has an $n-\pi^{*}$ transition at $460 \mathrm{~nm}$ and a $\pi-\pi^{*}$ transition at $314 \mathrm{~nm}$ (in DMSO at $298 \mathrm{~K}) .18 \mathrm{a}$ The larger red-shift of the $\mathrm{n}-\pi^{*}$ band compared to the $\pi-\pi^{*}$ was also reported for $2,2^{\prime}, 6,6^{\prime}-$ tetrafluoro-4,4'-diacetamidoazobenzene, ${ }^{18 a}$ suggesting this effect is due to substitution with electron donating groups. Photoswitchable ligand $\mathbf{3}$ undergoes reversible photoswitching with visible light (Figure 2c). Irradiation of $\mathbf{3}$ with an LED centered at $530 \mathrm{~nm}$ generated a photostationary state comprising $80 \%$ Z-3 (calculated from ${ }^{19} \mathrm{~F}$ NMR signal integrations, Figure $2 \mathrm{~b}$ and SI-4.1). Subsequent irradiation at $410 \mathrm{~nm}$ generated a new photostationary state comprising $85 \% \quad E-3$. The calculated absorption spectrum $^{35}$ of $Z-3$ shows an $n-\pi^{*}$ transition with an absorption maximum at $432 \mathrm{~nm}$, slightly red-shifted compared to unsubstituted or ester substituted orthofluoroazobenzenes $\left(\lambda_{\max }=417-421 \mathrm{~nm}\right){ }^{18 \mathrm{a}}$ The separation between the $n-\pi^{*}$ bands for the two isomers of $3\left(\Delta \lambda_{n-\pi^{*}}=\right.$ $33 \mathrm{~nm}$ ) is similar to that found for other orthofluoroazobenzenes with electron-donating groups in the para position, ${ }^{18 a}$ but less than that for the parent orthofluoroazobenzenes or examples with electron withdrawing groups $\left(\Delta \lambda_{n-\pi^{*}}=30\right.$ to $\left.50 \mathrm{~nm}\right){ }^{18 \mathrm{~b}}$ Nonetheless, selective photoswitching is still achieved between the isomers. Photoswitchable ligand $Z-3$ has a thermal half-life of $\approx 25$ days at $298 \mathrm{~K}$ (thermal barrier of $110 \mathrm{kJmol}^{-1}$, measured at $333 \mathrm{~K}$ in DMSO, see SI-4.3). Photoswitch 4 has similar properties to photoswitchable ligand 3. 
For example, photoswitch 4 has an $n-\pi^{*}$ absorption band at $462 \mathrm{~nm}$ and a $\pi-\pi^{*}$ band at $360 \mathrm{~nm}$, and $Z-4$ has a thermal half-life of $\approx 37$ days at $298 \mathrm{~K}$ (see SI-5 for details). Photoswitches $\mathbf{3}$ and $\mathbf{4}$ both have shorter half-lives compared to the parent ortho-fluoroazobenzene which has a half-life of 700 days (thermal barrier of $117 \mathrm{kJmol}^{-1}$, measured at 333-373 K in DMSO) ${ }^{18 b}$

a)
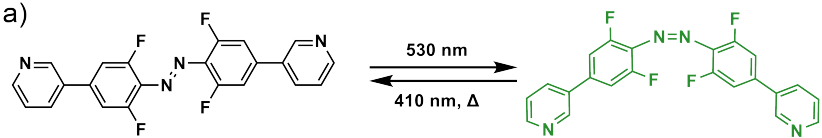

b)
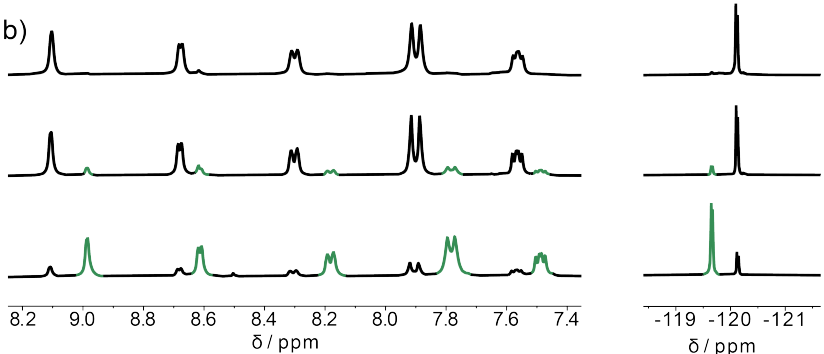

c)

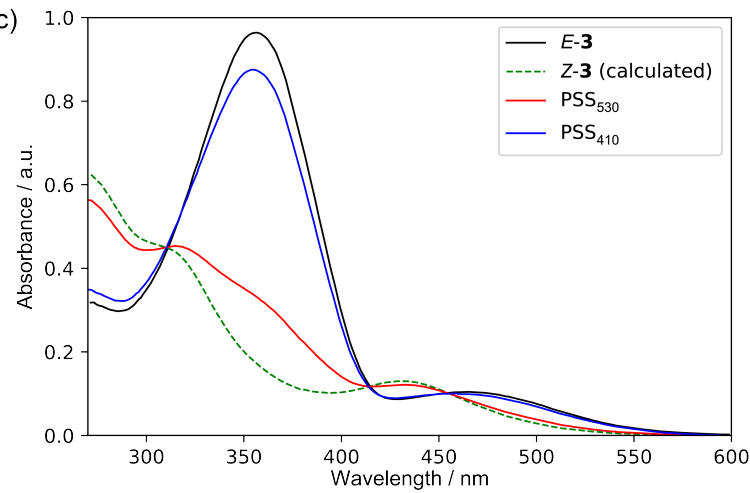

Figure 2. Photoswitching between $E-3$ and $Z-3$ monitored by b) ${ }^{1} \mathrm{H}$ and ${ }^{19} \mathrm{~F}$ NMR spectroscopy at $298 \mathrm{~K}$ in DMSO-d6. Irradiation at $410 \mathrm{~nm}$ generates a PSS containing 15\% Z-3. Irradiation at $530 \mathrm{~nm}$ generates a PSS containing $80 \%$ Z-3. Isomer ratios were calculated from ${ }^{19} \mathrm{~F}$ NMR signal integrations. c) UV-Vis spectroscopy at $298 \mathrm{~K}$ in DMSO. The spectrum of Z-3 was calculated using the isomer ration determined by ${ }^{19} \mathrm{~F}$ NMR signal integrations of a sample irradiated at $530 \mathrm{~nm}$.
Having characterized photoswitchable ligand 3, we next investigated its self-assembly with palladium(II) ions. When [Pd(CH $\left.\left.3{ }_{3}\right)_{4}\right]\left(\mathrm{BF}_{4}\right)_{2}$ was added to $E-3$ in DMSO-d 6 a new species was immediately formed as observed by ${ }^{1} \mathrm{H}$ and ${ }^{19} \mathrm{~F}$ NMR spectroscopy (Figure 3b, SI-6). Equilibration in the dark at room temperature over 10 days led to the formation of a new, lower symmetry, assembly comprising $69 \%$ of the mixture (Figure 3c). Using ${ }^{1} \mathrm{H}$ NMR diffusion (Figure $4 \mathrm{a}$ ) and ROESY NMR (Figure 4b) data we identified two separate species, with the higher symmetry species having a smaller hydrodynamic diameters (27 vs $31 \AA$ A). Similar self-assembly using a more soluble palladium salt ${ }^{36}$ gave the same two structures albeit with a slightly different relative abundance, see SI-7.

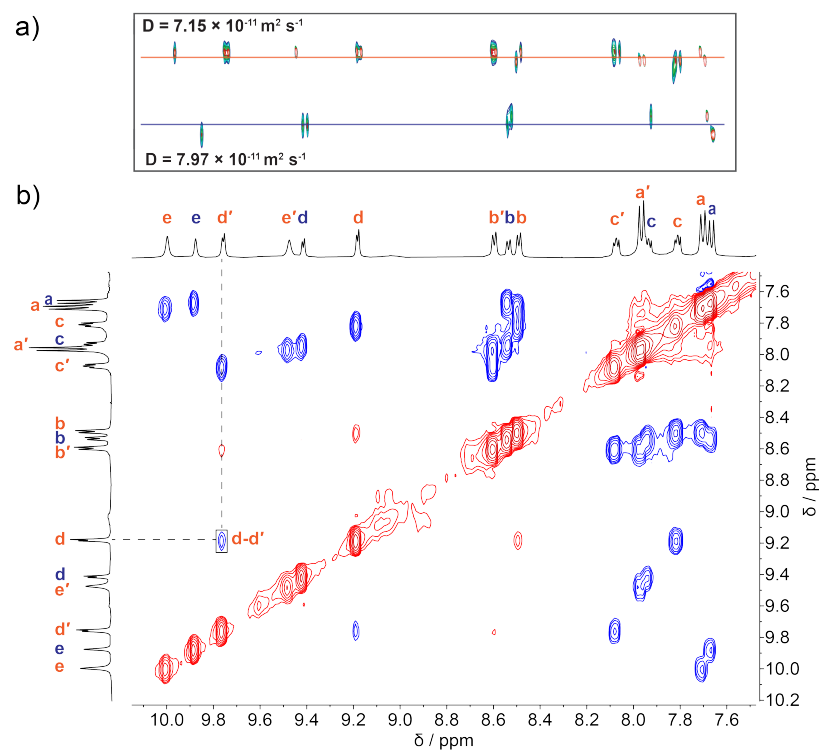

Figure 4. Identification of the ${ }^{1} \mathrm{H}$ NMR signals for the mixture of self-assembled species, $\left[\mathrm{Pd}_{3}(3)_{6}\right]^{6+}$ and $\left[\mathrm{Pd}_{4}(3)_{8}\right]^{8+}$. a) ${ }^{1} \mathrm{H}$

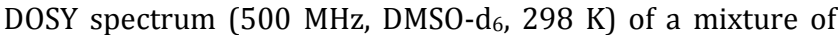
$\left[\mathrm{Pd}_{3}(3)_{6}\right]^{6+}$ and $\left[\mathrm{Pd}_{4}(3)_{8}\right]^{8+}$. Diffusion constants calculated based on fitting of the peak integrations (see SI-8.2). b) ${ }^{1} \mathrm{H}$ ROESY spectrum with the through-space interaction between peaks belonging to different ring systems highlighted.
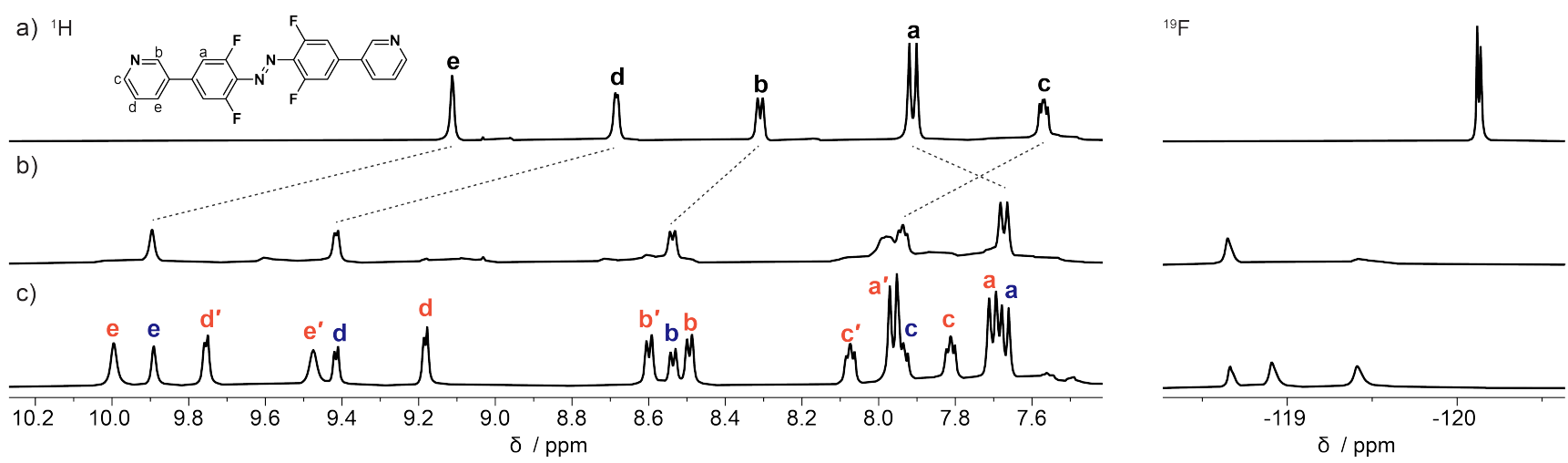

Figure 3. Formation of a mixture of $\left[\mathrm{Pd}_{3}(3)_{6}\right]^{6+}$ (blue) and $\left[\mathrm{Pd}_{4}(3)_{8}\right]^{8+}$ (red) in DMSO- $d_{6}$ monitored by ${ }^{1} \mathrm{H}$ NMR spectroscopy. ${ }^{1} \mathrm{H}$ NMR spectra of $E-3$ in DMSO- $d_{6}([3]=19 \mathrm{mM})$ a) before addition of palladium, b) immediately after addition of $\left[\mathrm{Pd}\left(\mathrm{CH}_{3} \mathrm{CN}_{4}\right]\left(\mathrm{BF}_{4}\right)_{2}\right.$ and c) after equilibration in the dark for 10 days. The signals for the $\left[\mathrm{Pd}_{4}(3)_{8}\right]^{8+}$ species denoted by a dash (') correspond to the single-bridged ligands. See SI-10 for assignment for $\left[\mathrm{Pd}_{3}(3)_{6}\right]^{6+}, \mathrm{SI}-11$ for assignment for $\left[\mathrm{Pd}_{4}(3)_{8}\right]^{8+}$. 
Characteristic downfield shifts of the ${ }^{1} \mathrm{H}$ NMR signals for pyridyl protons indicate coordination to the metal ion (see SI-8.1 for full details). ${ }^{37}$ In the initially formed species the ligand retains its original symmetry and the ${ }^{1} \mathrm{H}$ NMR signal for $\mathrm{H}^{\text {a }}$ (see Fig. 3 for atom labels) shifts upfield by $\approx 0.2$ ppm, consistent with shielding effects commonly seen for related structures. ${ }^{38,37 b}$ The lower symmetry species has a doubling of all ligand signals (Figure $3 \mathrm{c}$ ), with a significant upfield shift $(\approx 0.4 \mathrm{ppm})$ of the $\mathrm{H}^{\mathrm{e}}$ proton compared to the symmetric species. The ${ }^{19} \mathrm{~F}$ NMR spectrum confirms the reduced symmetry with two peaks observed for the lower symmetry species. The significant peak shifts observed in the NMR spectra did not allow unambiguous assignment of the $E / Z$-isomerization state. The UV-visible absorption spectrum of the mixture was also unhelpful for assigning the $E$ or $Z$ isomer composition (SI-15.1). Therefore, a degradation experiment was performed. Dimethylaminopyridine (DMAP) was added to the equilibrated mixture in the dark which rapidly disassembled the structures to form exclusively $E$-3 and [Pd(DMAP) $\left.)_{4}\right]\left(\mathrm{BF}_{4}\right)_{2}$ as seen by ${ }^{1} \mathrm{H}$ NMR spectroscopy (See SI-12). Due to the long thermal half-life of $Z-3$, this degradation experiment indicates that the observed ${ }^{1} \mathrm{H}$ NMR peak shifts and changes in the UV-visible absorption spectra are due to the constrained local environment or distortions of the $E-3$ ligand imposed by the structure, rather than isomerization of the ligand.

High resolution electrospray ionization mass spectrometry (ESI-MS) identified two major species, a $\left[\mathrm{Pd}_{3}(3)_{6}\right]^{6+}$ and a $\left[\mathrm{Pd}_{4}(3)_{8}\right]^{8+}$ assembly (Figure 5 , SI-9) with a range of charge states corresponding to sequential loss of $\mathrm{BF}_{4}^{-}$anions from these structures. The combination of NMR and MS data, together with preliminary molecular modelling, was used to propose the topologies of the self-assembled structures for $\left[\mathrm{Pd}_{3}(3)_{6}\right]^{6+}$ and a $\left[\mathrm{Pd}_{4}(3)_{8}\right]^{8+}$ (Figure $6 \mathrm{~b}$ and $6 \mathrm{c})$. For the $\left[\mathrm{Pd}_{3}(3)_{6}\right]^{6+}$ species, the NMR spectra indicates a highly symmetrical structure, which is assigned as a double-walled triangle. ${ }^{39}$

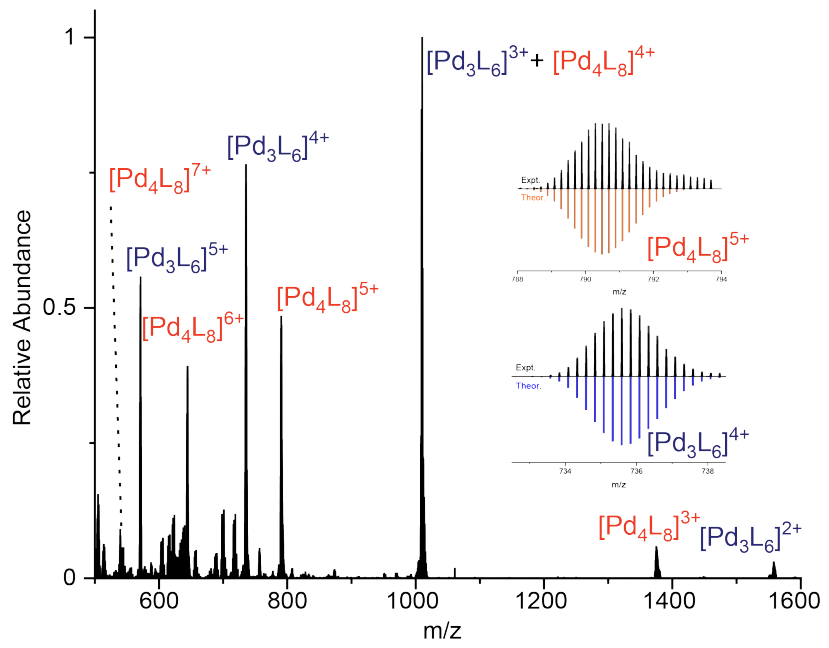

Figure 5. High resolution ESI-MS of a mixture of $\left[\mathrm{Pd}_{3}(3)_{6}\right]^{6+}$ and $\left[\mathrm{Pd}_{4}(3)_{8}\right]^{8+}$. The inset shows two peaks for the selfassembled species and their calculated isotope distribution. For other details see SI-9. a) Potential $M_{4} L_{8}$ topologies

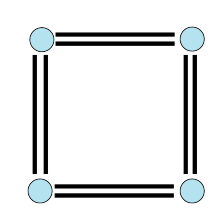

Double-Walled Square b)
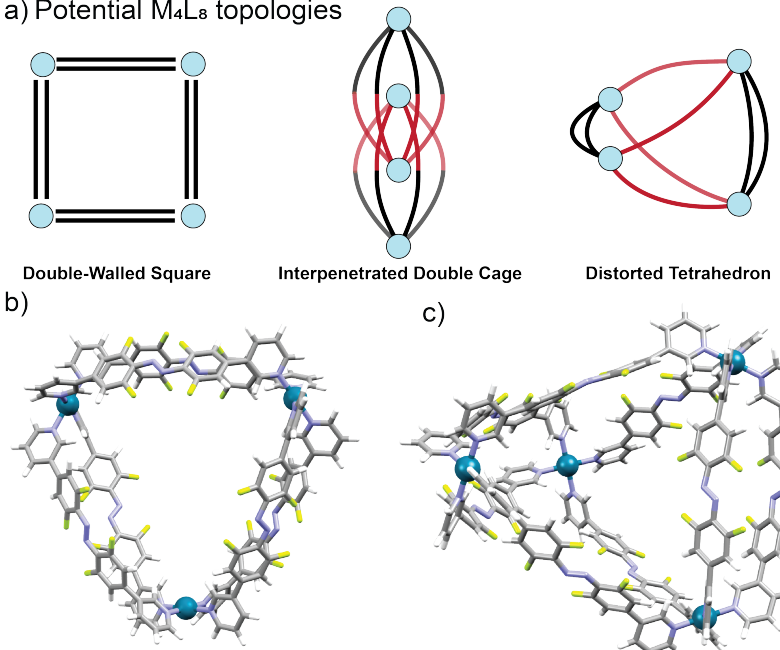

Distorted Tetrahedron

c)

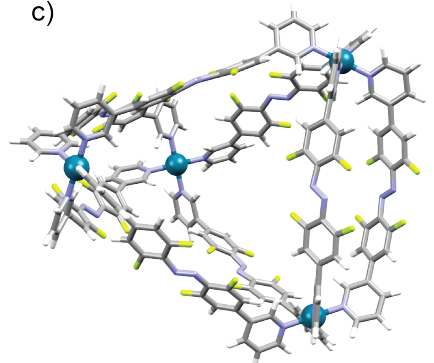

Figure 6. a) Possible topologies for the $\left[\mathrm{Pd}_{4}(3)_{8}\right]^{8+}$ composition. Blue spheres represent Pd(II) ions and black and red edges represent non-equivalent ligands. b) Proposed structure for the $\left[\mathrm{Pd}_{3}(3)_{6}\right]^{6+}$ assembly and c) Proposed structure for the $\left[\mathrm{Pd}_{4}(\mathbf{3})_{8}\right]^{8+}$ assembly.

Crude molecular modelling suggests the ligands are in close contact, consistent the downfield shift of the pyridyl signals for the ligand in the ${ }^{1} \mathrm{H}$ NMR spectrum. The modelled structure has a longest axis of $25 \AA$, which is in good agreement with the hydrodynamic diameter calculated from the NMR diffusion data (27 $\AA$ ), especially given the significant anisotropy of the structure.

For the species with composition $\left[\mathrm{Pd}_{4}(3)_{8}\right]^{8+}$, several possibilities can be considered (Figure 6a): a doublewalled square, ${ }^{39 b, 39 e}$ an interpenetrated double cage ${ }^{40}$ or a distorted tetrahedron. ${ }^{39 a, 39 h, 41}$ The double-walled square would nominally have $D_{4 \mathrm{~h}}$ symmetry with all pyridyl rings being equivalent. This is inconsistent with the observed number of signals in the NMR spectra. The interpenetrated double cage structure would show a doubling of the ${ }^{1} \mathrm{H}$ and ${ }^{19} \mathrm{~F}$ NMR signals as observed. However, in previous reports of such topologies the transient formation of a $\left[\mathrm{Pd}_{2} \mathrm{~L}_{4}\right]^{4+}$ cage was observed in the ${ }^{1} \mathrm{H}$ NMR spectrum and by ESI-MS. ${ }^{40 \mathrm{~b}}$

Such species were not observed for the current system and molecular modelling also suggests significant strain would be required in the $\left[\mathrm{Pd}_{2}(3)_{4}\right]^{4+}$ subunit. The structure is therefore proposed as a distorted tetrahedron with $\mathrm{C}_{2 \mathrm{v}}$ symmetry. Ligands with 3-pyridyl groups bridged by phenyl ${ }^{39 a, 41 b}$ or BINOL linkers ${ }^{41 a}$ have been previously assembled into analogous distorted tetrahedra with palladium(II), but the topology remains rare. ${ }^{39 a, 41 a, 41 b, 41 d, 39 h}$ For $\left[\mathrm{Pd}_{4}(3)_{8}\right]^{8+}$ the groups of signals from the non-equivalent ligands were assigned using 2D NMR techniques and by comparing to previously reported examples. ${ }^{39 a}$ The local environment for the double-bridged ligands is similar to that observed for the double-walled triangle $\left[\mathrm{Pd}_{3}(3)_{6}\right]^{6+}$ species. The single-bridged ligands are more similar to free $E-3$, especially the phenyl proton $\left(\mathrm{H}^{\mathrm{a}}\right)$ which is distal to coordinating pyridines. The molecular model suggests a longest axis (28 $\AA$ ) in agreement with the calculated hydrodynamic diameter $(31 \AA$ ) from the diffusion NMR data. 
Variable temperature ${ }^{1} \mathrm{H}$ NMR spectra (SI-8.3) confirmed the two species were in equilibrium. Increasing the temperature to $333 \mathrm{~K}$ gave a mixture containing $63 \%$ of the smaller $\left[\mathrm{Pd}_{3}(3)_{3}\right]^{6+}$ species. This is ascribed to entropic considerations, as proposed in other systems. ${ }^{42}$ The system initially remained out of equilibrium upon cooling to $298 \mathrm{~K}$, reaching the original distribution after 18 hours in the dark. This indicates that the double-walled triangle acts as a kinetic trap for the system, consistent with the initial observations upon combination of $E-3$ and $\left[\mathrm{Pd}\left(\mathrm{CH}_{3} \mathrm{CN}\right)_{4}\right]\left(\mathrm{BF}_{4}\right)_{2}$.

Having investigated the self-assembly properties of $E-3$, we next investigated the behavior of the $Z-3$ isomer. A sample of 3 was enriched to $80 \%$ Z-3 by irradiation with $530 \mathrm{~nm}$ light, then combined with $\left[\mathrm{Pd}\left(\mathrm{CH}_{3} \mathrm{CN}\right)_{4}\right]\left(\mathrm{BF}_{4}\right)_{2}$ in DMSO- $d_{6}$. The resulting poorly resolved ${ }^{1} \mathrm{H}$ NMR spectrum suggests the formation of non-distinct or polymeric products, which do not significantly resolve over time (see SI13). To understand the self-assembly behavior, we next considered the binding affinity of the ligand for palladium(II) centers. To the best of our knowledge, and despite their widespread use in supramolecular self-assembly, quantitative binding constants for simple pyridine derivatives to palladium(II) ions do not appear to be reported. To study a single 1:1 binding event, we used a palladium(II) complex with a tridentate terpyridine ligand (ttpy $=4^{\prime}-$ (para-tolyl)-2,2':6',2"'-terpyridine),

[Pd(ttpy)(DMSO)](BF $)_{2}$, which has a weakly bound solvent molecule that can be readily exchanged for the other ligands. We used 3-methylpyridine as a simple monodentate ligand (SI-3 for synthetic details). Isothermal titration calorimetry (ITC) was used to measure the 1:1 binding constant (see SI-14.1). The relative binding constant is $1.73 \times 10^{4} \mathrm{~mol}^{-1}$ in DMSO, equivalent to a binding energy of just $24 \mathrm{~kJ} \cdot \mathrm{mol}^{-1}$ at $298 \mathrm{~K}$. Similar ITC measurements with 3 and $[\mathrm{Pd}(\mathrm{ttpy})(\mathrm{DMSO})]\left(\mathrm{BF}_{4}\right)_{2}$ indicated only weaker binding $\left(K_{\mathrm{a}}<1000\right)$, although solubility difficulties prevented quantitative measurements. Competitive binding experiments monitored by ${ }^{1} \mathrm{H}$ NMR spectroscopy confirmed that 3 is nearly completely displaced from $[\mathrm{Pd}(\mathrm{ttpy})(\mathrm{DMSO})]\left(\mathrm{BF}_{4}\right)_{2}$ when one equivalent of 3methylpyridine is added (see SI-14.2), consistent with 3 being a surprisingly poor ligand for palladium(II). We also investigated the influence of palladium(II) ions on the photoswitching behavior of ligand 3. When 100 equivalents of $[\mathrm{Pd}(\mathrm{ttpy})(\mathrm{DMSO})]\left(\mathrm{BF}_{4}\right)_{2}$ was added to ligand $\mathbf{3}$ and the sample was irradiated with $530 \mathrm{~nm}$ light, the same thermal $Z \rightarrow E$ half-life in the dark was measured by UV-vis absorption, (see SI-4.3, SI-4.4). As ligand 3 has only weak affinity for palladium(II), its ability to assemble into discrete structures suggests that cooperativity is responsible for stabilizing the resulting self-assembled structures.

The distribution between $\left[\mathrm{Pd}_{3} \mathrm{~L}_{6}\right]^{6+}$ and $\left[\mathrm{Pd}_{4} \mathrm{~L}_{8}\right]^{8+}$ can be pumped away from equilibrium using light, even though $Z$ 3 did not self-assemble into well-defined structures with palladium(II) ions. After irradiating a mixture of $\left[\mathrm{Pd}_{3}(3)_{6}\right]^{6+}$ and $\left[\mathrm{Pd}_{4}(3)_{8}\right]^{8+}$ in DMSO- $d_{6}$ with $410 \mathrm{~nm}$ light for 10 minutes, ${ }^{1} \mathrm{H}$ and ${ }^{19} \mathrm{~F}$ NMR spectroscopy reveals a significant increase in the population of $\left[\mathrm{Pd}_{3}(3)_{6}\right]^{6+}$, while also showing the concomitant decrease of $\left[\mathrm{Pd}_{4}(3)_{8}\right]^{8+}($ Figure $7 \mathrm{~b}$, ii). No new signals were observed, suggesting no new well-defined self-assembled species were formed. This observation was reaffirmed by high-resolution ESIMS, the relative population of $\left[\mathrm{Pd}_{3}(3)_{6}\right]^{6+}$ increased after irradiation with $410 \mathrm{~nm}$ light (see SI-15). Irradiating the sample with $530 \mathrm{~nm}$ light for 10 minutes resulted in the deformation of the two species as seen in the poorly defined ${ }^{1} \mathrm{H}$ and ${ }^{19} \mathrm{~F}$ NMR spectra, suggesting the formation of polymeric species, or other low symmetry species (Figure $7 \mathrm{~b}$, iii). The large population of $\left[\mathrm{Pd}_{3}(3)_{6}\right]^{6+}$ could be recovered by irradiating the system again with $410 \mathrm{~nm}$ light for 10 minutes (Figure 7b, iv), demonstrating selective and reversible assembly and disassembly of the triangle species. After heating the sample at $60^{\circ} \mathrm{C}$ for 2 days the original distribution was largely recovered $\left(\left[\mathrm{Pd}_{3}(3)_{6}\right]^{6+}\right.$ : $\left[\mathrm{Pd}_{4}(3)_{8}\right]^{8+}=3: 4$, Figure $\left.7 \mathrm{~b}, \mathrm{v}\right)$ ), although some chemical shift changes and peak broadening had occurred. The broad peaks observed in the ${ }^{1} \mathrm{H}$ and ${ }^{19} \mathrm{~F}$ NMR spectra after irradiation are consistent with the involvement of $Z-3$ within the self-assembled species (Figure 7b, iii), either as structural components or as guest molecules. This effect is far more pronounced within $\left[\mathrm{Pd}_{4}(3)_{8}\right]^{8+}$, supporting the notion that $\left[\mathrm{Pd}_{4}(3)_{8}\right]^{8+}$ is more flexible and able to accommodate the mismatched ligand whereas $\left[\mathrm{Pd}_{3}(3)_{6}\right]^{6+}$ is more rigid and well-defined.

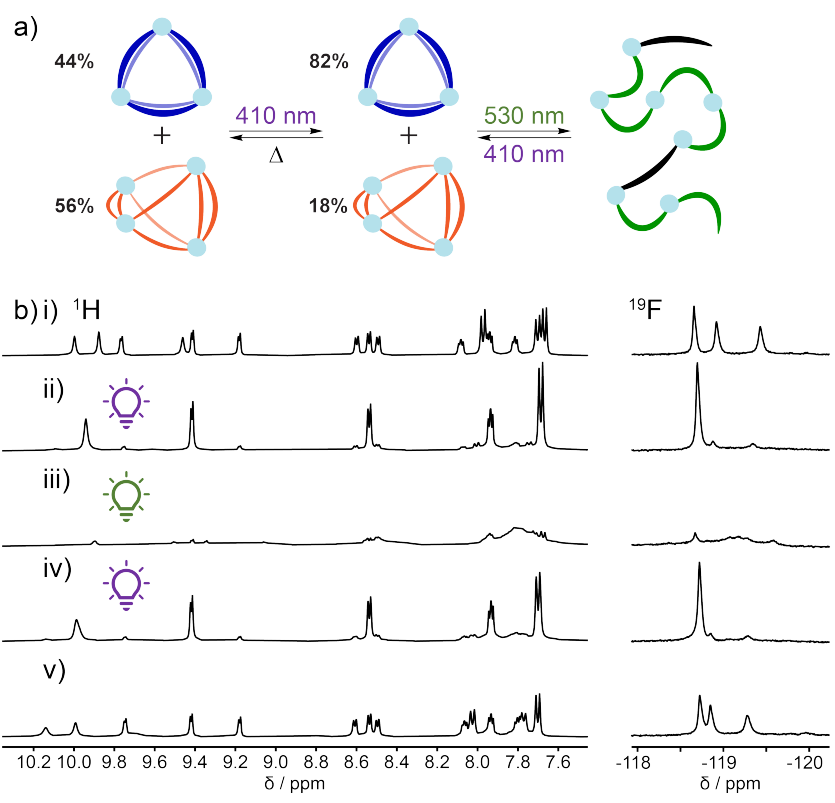

Figure 7. The response to light irradiation of a sample of $\left[\mathrm{Pd}_{3}(3)_{6}\right]^{6+}$ and $\left[\mathrm{Pd}_{4}(3)_{8}\right]^{8+}$ in DMSO- $d_{6}([3]=1.9 \mathrm{mM})$. a) Cartoon representation of the topology changes induced by irradiation. b) ${ }^{1} \mathrm{H}$ NMR and ${ }^{19} \mathrm{~F}$ spectra of i) a mixture of $\left[\mathrm{Pd}_{3}(3)_{6}\right]^{6+}$ and $\left[\mathrm{Pd}_{4}(3)_{8}\right]^{8+}$ in DMSO-d $6\left(44 \%\left[\mathrm{Pd}_{3}(3)_{6}\right]^{6+}\right)$; ii) the same sample after irradiation with $410 \mathrm{~nm}$ light for 10 minutes $\left(82 \%\left[\mathrm{Pd}_{3}(3)_{6}\right]^{6+}\right)$; iii) the same sample after irradiation with $530 \mathrm{~nm}$ light for 10 minutes; iv) the same sample after irradiation with $410 \mathrm{~nm}$ light for 10 minutes again; and v) the same sample after 2 days of being heated at $60^{\circ} \mathrm{C}$ followed by $6 \mathrm{~h}$ of equilibrating at room temperature.

The selective disassembly of $\left[\mathrm{Pd}_{4}(3)_{8}\right]^{8+}$ can be rationalized by considering the composition of ligands, the rate of ligand exchange for each species, and the constraints imposed on the photoswitching of ligand 3 while assembled. Variable temperature NMR experiments confirm the struc- 
tures are dynamic with exchange of ligands and solvent molecules, as is common for palladium(II)-pyridyl assemblies (see SI-8.3).43 If photoisomerization is suppressed within the self-assembled structures, as observed for a DTE-based cage, ${ }^{27 b}$ ligand 3 can only isomerize after dissociating from palladium. For the tetrahedron $\left[\mathrm{Pd}_{4}(3)_{8}\right]^{8+}$, a $E-3$ ligand can dissociate and photoisomerize, but the newly generated Z-3 ligand cannot reassemble into the same original structure. We propose that a metastable $\left[\mathrm{Pd}_{4}(3)_{7}\right]^{8+}$ structure is formed and the ligands rapidly rearrange to form the double-walled triangle, $\left[\mathrm{Pd}_{3}(3)_{6}\right]^{6+}$. As $\left[\mathrm{Pd}_{3}(\mathbf{3})_{6}\right]^{6+}$ is more inert, any free $E-3$ in solution will be kinetically trapped as $\left[\mathrm{Pd}_{3}(3)_{6}\right]^{6+}$. As such, irradiation with $410 \mathrm{~nm}$ light continuously pumps the system out-ofequilibrium to favour the formation of the less thermodynamically preferred $\left[\mathrm{Pd}_{3}(3)_{6}\right]^{6+}$. The PSS generated when irradiated with $530 \mathrm{~nm}$ light comprises only $20 \% E$-3, which appears too low to form a significant amount of $\left[\mathrm{Pd}_{3}(3)_{6}\right]^{6+}$. This finding is consistent with our experiments using a sample of enriched Z-3 and palladium(II) which also resulted in the same ill-defined mixtures.

The observed behavior is surprising as it results from a relatively small change $(\sim 20 \%)$ in the isomer distribution caused by irradiating with $410 \mathrm{~nm}$ light. Typically, stimuli responsive architectures are designed to maximize the proportion of components that are switched. This work offers a different approach, where small changes in isomer distribution can be amplified to significant changes within the system, similar to the sergeants-and-soldiers concept ${ }^{44}$ in self-sorting. To the best of our knowledge, this is the first example of a self-assembled system where the configuration can be controlled using only visible light and the resultant distribution contains the same sub-components as the equilibrium distribution.

\section{CONCLUSION}

We have shown that building visible-light switchable $o$ fluoroazobenzenes into palladium(II)-pyridyl selfassemblies leads to visible-light responsive systems. Irradiating with visible light reversibly redistributes the subcomponents, driving the system out-of-equilibrium to form the higher energy, but less labile, structure. Unlike previous examples, the distinct assemblies contain the same photoisomer of the ligand. This approach of pumping systems to metastable states exploits kinetic effects to amplify small changes in photoisomer distributions to generate large changes in structural distributions.

\section{Author Contributions}

$\dagger$ These authors contributed equally. The manuscript was written through contributions of all authors.

\section{Notes}

The authors declare no competing financial interests.

\section{ACKNOWLEDGMENT}

The Australian Research Council (JEB, FT170100094), the Australian Government (ADWK, Australian Postgraduate Award), are acknowledged for funding. We acknowledge the Mark Wainwright Analytical Centre at UNSW Sydney, for access to the NMR facility. We thank Prof. Paul Lusby and Prof. Dean Astumian for very helpful discussions.

\section{REFERENCES}

(1) For relevant reviews, see (a) McConnell, A. J.; Wood, C. S.; Neelakandan, P. P.; Nitschke, J. R. Stimuli-Responsive Metal-Ligand Assemblies. Chem. Rev. 2015, 115, 7729-7793; (b) Qu, D.-H.; Wang, Q.-C.; Zhang, Q.-W.; Ma, X.; Tian, H. Photoresponsive Host-Guest Functional Systems. Chem. Rev. 2015, 115, 7543-7588; (c) Wang, W.; Wang, Y.-X.; Yang, H.-B. Supramolecular transformations within discrete coordination-driven supramolecular architectures. Chem. Soc. Rev. 2016, 45, 2656-2693; (d) Goswami, A.; Saha, S.; Biswas, P. K.; Schmittel, M. (Nano)mechanical Motion Triggered by Metal Coordination: from Functional Devices to Networked Multicomponent Catalytic Machinery. Chem. Rev. 2020, 120, 125199.

(2) (a) Murase, T.; Sato, S.; Fujita, M. Switching the Interior Hydrophobicity of a Self-Assembled Spherical Complex through the Photoisomerization of Confined Azobenzene Chromophores. Angew. Chem. Int. Ed. 2007, 46, 5133-5136; (b) Kishi, N.; Akita, M.; Kamiya, M.; Hayashi, S.; Hsu, H.-F.; Yoshizawa, M. Facile Catch and Release of Fullerenes Using a Photoresponsive Molecular Tube. J. Am. Chem. Soc. 2013, 135, 12976-12979; (c) Park, J.; Sun, L.-B.; Chen, Y.-P.; Perry, Z.; Zhou, H.-C. Azobenzene-Functionalized Metal-Organic Polyhedra for the Optically Responsive Capture and Release of Guest Molecules. Angew. Chem. Int. Ed. 2014, 53, 58425846.

(3) (a) Scherer, M.; Caulder, D. L.; Johnson, D. W.; Raymond, K. N. Triple Helicate-Tetrahedral Cluster Interconversion Controlled by Host-Guest Interactions. Angew. Chem. Int. Ed. 1999, 38, 1587-1592; (b) Riddell, I. A.; Smulders, M. M. J.; Clegg, J. K.; Hristova, Y. R.; Breiner, B.; Thoburn, J. D.; Nitschke, J. R. Anion-induced reconstitution of a self-assembling system to express a chloridebinding Co10L15 pentagonal prism. Nat. Chem 2012, 4, 751-756; (c) Clegg, J. K.; Cremers, J.; Hogben, A. J.; Breiner, B.; Smulders, M. M. J.; Thoburn, J. D.; Nitschke, J. R. A stimuli responsive system of selfassembled anion-binding Fe4L68+ cages. Chem. Sci. 2013, 4, 68-76.

(4) (a) Mal, P.; Schultz, D.; Beyeh, K.; Rissanen, K.; Nitschke, J. R. An Unlockable-Relockable Iron Cage by Subcomponent Self-Assembly. Angew. Chem. Int. Ed. 2008, 47, 8297-8301; (b) Lusby, P. J.; Müller, P.; Pike, S. J.; Slawin, A. M. Z. Stimuli-Responsive Reversible Assembly of 2D and 3D Metallosupramolecular Architectures. J. Am. Chem. Soc. 2009, 131, 16398-16400.

(5) (a) Zheng, Y.-R.; Lan, W.-J.; Wang, M.; Cook, T. R.; Stang, P. J. Designed Post-Self-Assembly Structural and Functional Modifications of a Truncated Tetrahedron. J. Am. Chem. Soc. 2011, 133, 17045-17055; (b) Henkelis, J. J.; Fisher, J.; Warriner, S. L.; Hardie, M. J. Solvent-Dependent Self-Assembly Behaviour and Speciation Control of Pd6L8 Metallo-supramolecular Cages. Chem.Eur. J. 2014, 20, 4117-4125; (c) Hardy, M.; Struch, N.; Holstein, J. J.; Schnakenburg, G.; Wagner, N.; Engeser, M.; Beck, J.; Clever, G. H.; Lützen, A. Dynamic Complex-to-Complex Transformations of Heterobimetallic Systems Influence the Cage Structure or Spin State of Iron(II) Ions. Angew. Chem. Int. Ed. 2020, 59, 3195-3200.

(6) (a) Kilbas, B.; Mirtschin, S.; Scopelliti, R.; Severin, K. A solventresponsive coordination cage. Chem. Sci. 2012, 3, 701-704; (b) Zarra, S.; Clegg, J. K.; Nitschke, J. R. Selective Assembly and Disassembly of a Water-Soluble Fe10L15 Prism. Angew. Chem. Int. Ed. 2013, 52, 4837-4840.

(7) (a) Siewertsen, R.; Neumann, H.; Buchheim-Stehn, B.; Herges, R.; Näther, C.; Renth, F.; Temps, F. Highly Efficient Reversible Z-E Photoisomerization of a Bridged Azobenzene with Visible Light through Resolved S1(n $\left.\pi^{*}\right)$ Absorption Bands. J. Am. Chem. Soc. 2009, 131, 15594-15595; (b) Samanta, S.; Qin, C.; Lough, A. J.; Woolley, G. A. Bidirectional photocontrol of peptide conformation with a bridged azobenzene derivative. Angew. Chem. 2012, 51, 64526455; (c) Fukaminato, T.; Hirose, T.; Doi, T.; Hazama, M.; Matsuda, K.; Irie, M. Molecular design strategy toward diarylethenes that photoswitch with visible light. J. Am. Chem. Soc. 2014, 136, 1714517154; (d) Yang, Y.; Hughes, R. P.; Aprahamian, I. Near-infrared light activated azo-BF2 switches. J. Am. Chem. Soc. 2014, 136, 13190-13193; (e) Hammerich, M.; Schutt, C.; Stahler, C.; Lentes, P.; Rohricht, F.; Hoppner, R.; Herges, R. Heterodiazocines: Synthesis and Photochromic Properties, Trans to Cis Switching within the Biooptical Window. J. Am. Chem. Soc. 2016, 138, 13111-13114; (f) Petermayer, C.; Dube, H. Indigoid Photoswitches: Visible Light Responsive Molecular Tools. Acc. Chem. Res. 2018, 51, 1153-1163; 
(g) Li, Z.; He, C.; Lu, Z.; Li, P.; Zhu, Y.-P. Recent progress in allvisible-light-triggered diarylethenes. Dyes Pigm. 2020, 182.

(8) (a) Mallo, N.; Foley, E. D.; Iranmanesh, H.; Kennedy, A. D. W.; Luis, E. T.; Ho, J.; Harper, J. B.; Beves, J. E. Structure-function relationships of donor-acceptor Stenhouse adduct photochromic switches. Chem. Sci. 2018, 9, 8242-8252; (b) Wang, L.; Li, Q. Photochromism into nanosystems: towards lighting up the future nanoworld. Chem. Soc. Rev. 2018, 47, 1044-1097.

(9) (a) Russew, M.-M.; Hecht, S. Photoswitches: From Molecules to Materials. Advanced Materials 2010, 22, 3348-3360; (b) Brieke, C.; Rohrbach, F.; Gottschalk, A.; Mayer, G.; Heckel, A. Light-Controlled Tools. Angew. Chem. Int. Ed. 2012, 51, 8446-8476; (c) Bléger, D.; Hecht, S. Visible-Light-Activated Molecular Switches. Angew. Chem. Int. Ed. 2015, 54, 11338-11349.

(10) (a) Larik, F. A.; Fillbrook, L. L.; Nurttila, S. S.; Martin, A. D.; Kuchel, R. P.; Al Taief, K.; Bhadbhade, M.; Beves, J. E.; Thordarson, P. Ultra-Low Molecular Weight Photoswitchable Hydrogelators. Angew. Chem. Int. Ed. 2021, 60, 6764-6770; (b) Panja, S.; Adams, D. J. Stimuli responsive dynamic transformations in supramolecular gels. Chem. Soc. Rev. 2021, 50, 5165-5200.

(11) Li, C.; Iscen, A.; Sai, H.; Sato, K.; Sather, N. A.; Chin, S. M.; Alvarez, Z.; Palmer, L. C.; Schatz, G. C.; Stupp, S. I. Supramolecularcovalent hybrid polymers for light-activated mechanical actuation. Nat. Mater. 2020, 19, 900-909.

(12) (a) Kunihiro, I. Photoalignment of Liquid-Crystal Systems. Chem. Rev. 2000, 100, 1847-1873; (b) Moran, M. J.; Magrini, M.; Walba, D. M.; Aprahamian, I. Driving a Liquid Crystal Phase Transition Using a Photochromic Hydrazone. J. Am. Chem. Soc. 2018, 140, 1362313627.

(13) (a) Liu, M.; Yan, X.; Hu, M.; Chen, X.; Zhang, M.; Zheng, B.; Hu, X.; Shao, S.; Huang, F. Photoresponsive Host-Guest Systems Based on a New Azobenzene-Containing Crytpand. Org. Lett. 2010, 12, 2558-2561; (b) MacDonald, T. S. C.; Feringa, B. L.; Price, W. S.; Wezenberg, S. J.; Beves, J. E. Controlled Diffusion of Photoswitchable Receptors by Binding Anti-electrostatic HydrogenBonded Phosphate Oligomers. J. Am. Chem. Soc. 2020, 142, 2001420020.

(14) Velema, W. A.; Szymanski, W.; Feringa, B. L. Photopharmacology: Beyond Proof of Principle. J. Am. Chem. Soc. 2014, 136, 2178-2191

(15) (a) Ragazzon, G.; Baroncini, M.; Silvi, S.; Venturi, M.; Credi, A. Light-powered autonomous and directional molecular motion of a dissipative self-assembling system. Nat. Nanotechnol. 2015, 10, 7075; (b) Kathan, M.; Hecht, S. Photoswitchable molecules as key ingredients to drive systems away from the global thermodynamic minimum. Chem. Soc. Rev. 2017, 46, 5536-5550; (c) Kathan, M.; Eisenreich, F.; Jurissek, C.; Dallmann, A.; Gurke, J.; Hecht, S. Lightdriven molecular trap enables bidirectional manipulation of dynamic covalent systems. Nat. Chem. 2018, 10, 1031-1036; (d) Canton, M.; Groppi, J.; Casimiro, L.; Corra, S.; Baroncini, M.; Silvi, S.; Credi, A. Second-Generation Light-Fueled Supramolecular Pump. J. Am. Chem. Soc. 2021, 143, 10890-10894; (e) Corra, S.; Casimiro, L.; Baroncini, M.; Groppi, J.; La Rosa, M.; Tranfić Bakić, M.; Silvi, S.; Credi, A. Artificial Supramolecular Pumps Powered by Light. Chem.- Eur. J. 2021, 27, 11076-11083.

(16) Bandara, H. M.; Burdette, S. C. Photoisomerization in different classes of azobenzene. Chem. Soc. Rev. 2012, 41, 1809-1825.

(17) (a) Siewertsen, R.; Neumann, H.; Buchheim-Stehn, B.; Herges, R.; Naether, C.; Renth, F.; Temps, F. Highly Efficient Reversible Z-E Photoisomerization of a Bridged Azobenzene with Visible Light through Resolved S-1(n pi*) Absorption Bands. J. Am. Chem. Soc. 2009, 131, 15594-15595; (b) Beharry, A. A.; Sadovski, O.; Woolley, G. A. Azobenzene Photoswitching without Ultraviolet Light. J. Am. Chem. Soc. 2011, 133, 19684-19687; (c) Beharry, A. A.; Woolley, G. A. Azobenzene photoswitches for biomolecules. Chem. Soc. Rev. 2011, 40, 4422-4437; (d) Samanta, S.; Babalhavaeji, A.; Dong, M. X.; Woolley, G. A. Photoswitching of ortho-substituted azonium ions by red light in whole blood. Angew. Chem. Int. Ed. 2013, 52, 1412714130; (e) Samanta, S.; Beharry, A. A.; Sadovski, O.; McCormick, T. M.; Babalhavaeji, A.; Tropepe, V.; Woolley, G. A. Photoswitching Azo Compounds in Vivo with Red Light. J. Am. Chem. Soc. 2013, 135, 9777-9784; (f) Dong, M.; Babalhavaeji, A.; Hansen, M. J.; Kálmán, L.; Woolley, G. A. Red, far-red, and near infrared photoswitches based on azonium ions. Chem. Commun. 2015, 51, 12981-12984; (g) Dong, M.; Babalhavaeji, A.; Samanta, S.; Beharry, A. A.; Woolley, G. A. Red-Shifting Azobenzene Photoswitches for in
Vivo Use. Acc. Chem. Res. 2015, 48, 2662-2670; (h) Dong, M.; Babalhavaeji, A.; Collins, C. V.; Jarrah, K.; Sadovski, O.; Dai, Q.; Woolley, G. A. Near-Infrared Photoswitching of Azobenzenes under Physiological Conditions. J. Am. Chem. Soc. 2017, 139, 1348313486; (i) Kolarski, D.; Szymanski, W.; Feringa, B. L. Two-Step, One-Pot Synthesis of Visible-Light-Responsive 6-Azopurines. Org. Lett. 2017, 19, 5090-5093; (j) Lentes, P.; Stadler, E.; Röhricht, F.; Brahms, A.; Gröbner, J.; Sönnichsen, F. D.; Gescheidt, G.; Herges, R. Nitrogen Bridged Diazocines: Photochromes Switching within the Near-Infrared Region with High Quantum Yields in Organic Solvents and in Water. J. Am. Chem. Soc. 2019, 141, 13592-13600

(18) (a) Bléger, D.; Schwarz, J.; Brouwer, A. M.; Hecht, S. oFluoroazobenzenes as Readily Synthesized Photoswitches Offering Nearly Quantitative Two-Way Isomerization with Visible Light. $J$. Am. Chem. Soc. 2012, 134, 20597-20600; (b) Knie, C.; Utecht, M.; Zhao, F.; Kulla, H.; Kovalenko, S.; Brouwer, A. M.; Saalfrank, P.; Hecht, S.; Bléger, D. ortho-Fluoroazobenzenes: Visible Light Switches with Very Long-Lived Z Isomers. Chem.- Eur. J. 2014, 20, 16492-16501; (c) Iamsaard, S.; Anger, E.; Aßhoff, S. J.; Depauw, A.; Fletcher, S. P.; Katsonis, N. Fluorinated Azobenzenes for ShapePersistent Liquid Crystal Polymer Networks. Angew. Chem. Int. Ed. 2016, 55, 9908-9912; (d) Liu, Q.; Dong, H.; Li, Y.; Li, H.; Chen, D.; Wang, L.; Xu, Q.; Lu, J. Improving Memory Performances by Adjusting the Symmetry and Polarity of O-Fluoroazobenzene-Based Molecules. Chem.-Asian J. 2016, 11, 512-519; (e) Moreno, J.; Grubert, L.; Schwarz, J.; Bléger, D.; Hecht, S. Efficient Sensitized $\mathrm{Z} \rightarrow \mathrm{E}$ Photoisomerization of an Iridium(III)-Azobenzene Complex over a Wide Concentration Range. Chem.- Eur. J. 2017, 23, 1409014095; (f) Opie, C. R.; Kumagai, N.; Shibasaki, M. Reversible Stereoselective Folding/Unfolding Fueled by the Interplay of Photoisomerism and Hydrogen Bonding. Angew. Chem. Int. Ed. 2017, 56, 3349-3353; (g) Mutruc, D.; Goulet-Hanssens, A.; Fairman, S.; Wahl, S.; Zimathies, A.; Knie, C.; Hecht, S. Modulating Guest Uptake in Core-Shell MOFs with Visible Light. Angew. Chem. Int. Ed. 2019, 58, 12862-12867; (h) Nieland, E.; Topornicki, T.; Kunde, T.; Schmidt, B. M. [2+2] Halogen-bonded boxes employing azobenzenes. Chem. Commun. 2019, 55, 8768-8771; (i) Nieland, E.; Weingart, O.; Schmidt, B. M. Fluorinated azobenzenes as supramolecular halogenbonding building blocks. Beilstein J. Org. Chem. 2019, 15, 20132019; (j) Aggarwal, K.; Kuka, T. P.; Banik, M.; Medellin, B. P.; Ngo, C. Q.; Xie, D.; Fernandes, Y.; Dangerfield, T. L.; Ye, E.; Bouley, B.; Johnson, K. A.; Zhang, Y. J.; Eberhart, J. K.; Que, E. L. Visible Light Mediated Bidirectional Control over Carbonic Anhydrase Activity in Cells and in Vivo Using Azobenzenesulfonamides. J. Am. Chem. Soc. 2020, 142, 14522-14531.

(19) (a) Kusukawa, T.; Fujita, M. "Ship-in-a-Bottle" Formation of Stable Hydrophobic Dimers of cis-Azobenzene and -Stilbene Derivatives in a Self-Assembled Coordination Nanocage. J. Am. Chem. Soc. 1999, 121, 1397-1398; (b) Pesce, L.; Perego, C.; Grommet, A. B.; Klajn, R.; Pavan, G. M. Molecular Factors Controlling the Isomerization of Azobenzenes in the Cavity of a Flexible Coordination Cage. J. Am. Chem. Soc. 2020, 142, 9792-9802.

(20) (a) Samanta, D.; Galaktionova, D.; Gemen, J.; Shimon, L. J. W.; Diskin-Posner, Y.; Avram, L.; Král, P.; Klajn, R. Reversible chromism of spiropyran in the cavity of a flexible coordination cage. Nature Communications 2018, 9, 641; (b) Hanopolskyi, A. I.; De, S.; Białek, M. J.; Diskin-Posner, Y.; Avram, L.; Feller, M.; Klajn, R. Reversible switching of arylazopyrazole within a metal-organic cage. Beilstein J. Org. Chem. 2019, 15, 2398-2407.

(21) (a) Yagai, S.; Nakajima, T.; Karatsu, T.; Saito, K.-i.; Kitamura, A. Phototriggered Self-Assembly of Hydrogen-Bonded Rosette. J. Am. Chem. Soc. 2004, 126, 11500-11508; (b) Wei, L.; Han, S. T.; Jin, T. T.; Zhan, T. G.; Liu, L. J.; Cui, J.; Zhang, K. D. Towards photoswitchable quadruple hydrogen bonds via a reversible "photolocking" strategy for photocontrolled self-assembly. Chem. Sci. 2020, 12, 1762-1771.

(22) Stuckhardt, C.; Roke, D.; Danowski, W.; Otten, E.; Wezenberg, S. J.; Feringa, B. L. A chiral self-sorting photoresponsive coordination cage based on overcrowded alkenes. Beilstein J. Org. Chem. 2019, 15, 2767-2773

(23) (a) Irie, M. Diarylethenes for Memories and Switches. Chem. Rev. 2000, 100, 1685-1716; (b) Pu, S.-Z.; Sun, Q.; Fan, C.-B.; Wang, R.-J.; Liu, G. Recent advances in diarylethene-based multi-responsive molecular switches. J. Mater. Chem. C 2016, 4, 3075-3093. 
(24) Li, M.; Chen, L.-J.; Cai, Y.; Luo, Q.; Li, W.; Yang, H.-B.; Tian, H.; Zhu, W.-H. Light-Driven Chiral Switching of Supramolecular Metallacycles with Photoreversibility. Chem 2019, 5, 634-648.

(25) Li, Z.-Y.; Dai, J.-W.; Damjanović, M.; Shiga, T.; Wang, J.-H.; Zhao, J.; Oshio, H.; Yamashita, M.; Bu, X.-H. Structure Switching and Modulation of the Magnetic Properties in Diarylethene-Bridged Metallosupramolecular Compounds by Controlled CoordinationDriven Self-Assembly. Angew. Chem. Int. Ed. 2019, 58, 4339-4344.

(26) Oldknow, S.; Martir, D. R.; Pritchard, V. E.; Blitz, M. A.; Fishwick, C. W. G.; Zysman-Colman, E.; Hardie, M. J. Structure-switching M3L2 Ir(III) coordination cages with photo-isomerising azo-aromatic linkers. Chem. Sci. 2018, 9, 8150-8159.

(27) (a) Han, M.; Michel, R.; He, B.; Chen, Y.-S.; Stalke, D.; John, M.; Clever, G. H. Light-Triggered Guest Uptake and Release by a Photochromic Coordination Cage. Angew. Chem. Int. Ed. 2013, 52, 1319-1323; (b) Han, M.; Luo, Y.; Damaschke, B.; Gómez, L.; Ribas, X.; Jose, A.; Peretzki, P.; Seibt, M.; Clever, G. H. Light-Controlled Interconversion between a Self-Assembled Triangle and a Rhombicuboctahedral Sphere. Angew. Chem. Int. Ed. 2016, 55, 445 449; (c) Li, R.-J.; Han, M.; Tessarolo, J.; Holstein, J. J.; Lübben, J.; Dittrich, B.; Volkmann, C.; Finze, M.; Jenne, C.; Clever, G. H. Successive Photoswitching and Derivatization Effects in Photochromic Dithienylethene-Based Coordination Cages. ChemPhotoChem 2019, 3, 378-383; (d) Li, R. J.; Holstein, J. J.; Hiller, W. G.; Andreasson, J.; Clever, G. H. Mechanistic Interplay between Light Switching and Guest Binding in Photochromic Pd(2)Dithienylethene(4) Coordination Cages. J. Am. Chem. Soc. 2019, 141, 2097-2103; (e) Li, R. J.; Tessarolo, J.; Lee, H.; Clever, G. H. Multi-stimuli Control over Assembly and Guest Binding in Metallo-supramolecular Hosts Based on Dithienylethene Photoswitches. J. Am. Chem. Soc. 2021, 143, 3865-3873.

(28) (a) Wei, S.-C.; Pan, M.; Fan, Y.-Z.; Liu, H.; Zhang, J.; Su, C.-Y. Creating Coordination-Based Cavities in a Multiresponsive Supramolecular Gel. Chem.- Eur. J. 2015, 21, 7418-7427; (b) Gu, Y.; Alt, E. A.; Wang, H.; Li, X.; Willard, A. P.; Johnson, J. A. Photoswitching topology in polymer networks with metal-organic cages as crosslinks. Nature 2018, 560, 65-69.

(29) Sun, S.-S.; Anspach, J. A.; Lees, A. J. Self-Assembly of TransitionMetal-Based Macrocycles Linked by Photoisomerizable Ligands: Examples of Photoinduced Conversion of Tetranuclear-Dinuclear Squares. Inorg. Chem. 2002, 41, 1862-1869.

(30) Yan, X.; Xu, J.-F.; Cook, T. R.; Huang, F.; Yang, Q.-Z.; Tung, C.-H.; Stang, P. J. Photoinduced transformations of stiff-stilbene-based discrete metallacycles to metallosupramolecular polymers. Proc. Natl Acad. Sci. U. S. A. 2014, 111, 8717-8722.

(31) This could be reversed by heating, leading to thermal isomerization and reformation of the original assembly. The conversion was very slow, taking over $20 \mathrm{~h}$ to reach a photostationary state.

(32) The precursor 4,4'-boronic ester shows limited reactivity for Suzuki coupling, evidenced by the isolation and single crystal X-ray structure of the mono coupled product (see SI-2.4).

(33) (a) Okumura, S.; Lin, C.-H.; Takeda, Y.; Minakata, S. Oxidative Dimerization of (Hetero)aromatic Amines Utilizing t-BuOI Leading to (Hetero)aromatic Azo Compounds: Scope and Mechanistic Studies. J. Org. Chem. 2013, 78, 12090-12105; (b) John, A. A.; Lin, Q. Synthesis of Azobenzenes Using N-Chlorosuccinimide and 1,8Diazabicyclo[5.4.0]undec-7-ene (DBU). J. Org. Chem. 2017, 82, 9873-9876.

(34) No shift in NMR signals were observed after solid K2CO3 was added to the sample, indicating that 3 is not protonated when isolated (see SI 2.3)

(35) Calculated using the 19F NMR signal integrations upon irradiation at $530 \mathrm{~nm}$

(36) Tateishi, T.; Takahashi, S.; Okazawa, A.; Martí-Centelles, V.; Wang, J.; Kojima, T.; Lusby, P. J.; Sato, H.; Hiraoka, S. Navigated SelfAssembly of a Pd2L4 Cage by Modulation of an Energy Landscape under Kinetic Control. J. Am. Chem. Soc. 2019, 141, 19669-19676.

(37) (a) Lewis, J. E. M.; Gavey, E. L.; Cameron, S. A.; Crowley, J. D. Stimuli-responsive Pd2L4 metallosupramolecular cages: towards targeted cisplatin drug delivery. Chem. Sci. 2012, 3, 778-784; (b) Shen, C.; Kennedy, A. D. W.; Donald, W. A.; Torres, A. M.; Price, W. S.; Beves, J. E. Self-assembled supramolecular cages containing dinuclear ruthenium(II) polypyridyl complexes. Inorg. Chim. Acta 2017, $458,122-128$.
(38) (a) Han, M.; Engelhard, D. M.; Clever, G. H. Self-assembled coordination cages based on banana-shaped ligands. Chem. Soc. Rev. 2014, 43, 1848-1860; (b) Preston, D.; Barnsley, J. E.; Gordon, K. C.; Crowley, J. D. Controlled Formation of Heteroleptic [Pd2(La)2(Lb)2]4+ Cages. J. Am. Chem. Soc. 2016, 138, 1057810585.

(39) (a) Chand, D. K.; Biradha, K.; Kawano, M.; Sakamoto, S.; Yamaguchi, K.; Fujita, M. Dynamic Self-Assembly of an M3L6 Molecular Triangle and an M4L8 Tetrahedron from Naked PdII Ions and Bis(3-pyridyl)-Substituted Arenes. Chem.-Asian J. 2006, 1, 8290; (b) Suzuki, K.; Kawano, M.; Fujita, M. Solvato-controlled assembly of Pd3L6 and Pd4L8 coordination "boxes". Angew. Chem. Int. Ed. 2007, 46, 2819-2822; (c) Samanta, D.; Mukherjee, P. S. Component Selection in the Self-Assembly of Palladium(II) Nanocages and Cage-to-Cage Transformations. Chem.- Eur. J. 2014 20, 12483-12492; (d) Jurček, O.; Bonakdarzadeh, P.; Kalenius, E.; Linnanto, J. M.; Groessl, M.; Knochenmuss, R.; Ihalainen, J. A.; Rissanen, K. Superchiral Pd3L6 Coordination Complex and Its Reversible Structural Conversion into Pd3L3Cl6 Metallocycles. Angew. Chem. Int. Ed. 2015, 54, 15462-15467; (e) Kai, S.; Tateishi, T.; Kojima, T.; Takahashi, S.; Hiraoka, S. Self-Assembly of a Pd4L8 Double-Walled Square Takes Place through Two Kinds of Metastable Species. Inorg. Chem. 2018, 57, 13083-13086; (f) Tateishi, T.; Kai, S.; Sasaki, Y.; Kojima, T.; Takahashi, S.; Hiraoka, S. Two dominant self-assembly pathways to a Pd3L6 double-walled triangle. Chem. Commun. 2018, 54, 7758-7761; (g) Rota Martir, D.; Delforce, L.; Cordes, D. B.; Slawin, A. M. Z.; Warriner, S. L.; Jacquemin, D.; Zysman-Colman, E. A Pd3L6 supramolecular cage incorporating photoactive [2.2]paracyclophane units. Inorg. Chem. Front. 2020, 7, 232-238; (h) Tessarolo, J.; Lee, H.; Sakuda, E.; Umakoshi, K.; Clever, G. H. Integrative Assembly of Heteroleptic Tetrahedra Controlled by Backbone Steric Bulk. J. Am. Chem. Soc. 2021, 143, 6339-6344.

(40) (a) Fukuda, M.; Sekiya, R.; Kuroda, R. A Quadruply Stranded Metallohelicate and Its Spontaneous Dimerization into an Interlocked Metallohelicate. Angew. Chem. Int. Ed. 2008, 47, 706-710; (b) Freye, S.; Hey, J.; Torras-Galán, A.; Stalke, D.; Herbst-Irmer, R.; John, M.; Clever, G. H. Allosteric Binding of Halide Anions by a New Dimeric Interpenetrated Coordination Cage. Angew. Chem. Int. Ed. 2012, 51, 2191-2194; (c) Frank, M.; Johnstone, M. D.; Clever, G. H. Interpenetrated Cage Structures. Chem.- Eur. J. 2016, 22, 1410414125 .

(41) (a) Klein, C.; Gütz, C.; Bogner, M.; Topić, F.; Rissanen, K.; Lützen, A. A New Structural Motif for an Enantiomerically Pure Metallosupramolecular Pd4L8 Aggregate by Anion Templating. Angew. Chem. Int. Ed. 2014, 53, 3739-3742; (b) Jansze, S. M.; Cecot, G.; Wise, M. D.; Zhurov, K. O.; Ronson, T. K.; Castilla, A. M.; Finelli, A.; Pattison, P.; Solari, E.; Scopelliti, R.; Zelinskii, G. E.; Vologzhanina, A. V.; Voloshin, Y. Z.; Nitschke, J. R.; Severin, K. Ligand Aspect Ratio as a Decisive Factor for the Self-Assembly of Coordination Cages. J. Am. Chem. Soc. 2016, 138, 2046-2054; (c) Tateishi, T.; Kojima, T.; Hiraoka, S. Multiple Pathways in the SelfAssembly Process of a Pd4L8 Coordination Tetrahedron. Inorg. Chem. 2018, 57, 2686-2694; (d) Li, R. J.; Fadaei-Tirani, F.; Scopelliti, R.; Severin, K. Tuning the Size and Geometry of Heteroleptic Coordination Cages by Varying the Ligand Bent Angle. Chem.- Eur. J. 2021, 27, 9439-9445.

(42) (a) Piguet, C.; Borkovec, M.; Hamacek, J.; Zeckert, K. Strict selfassembly of polymetallic helicates: the concepts behind the semantics. Coord. Chem. Rev. 2005, 249, 705-726; (b) Hamacek, J.; Borkovec, M.; Piguet, C. Simple thermodynamics for unravelling sophisticated self-assembly processes. Dalton Trans. 2006, 10.1039/b518461d, 1473-1490; (c) Weilandt, T.; Troff, R. W.; Saxell, H.; Rissanen, K.; Schalley, C. A. Metallo-Supramolecular Self-Assembly: the Case of Triangle-Square Equilibria. Inorg. Chem. 2008, 47, 7588-7598.

(43) (a) Bugarčić, Ž. D.; Petrović, B.; Zangrando, E. Kinetics and mechanism of the complex formation of $[\mathrm{Pd}(\mathrm{NNN}) \mathrm{Cl}]+$ with pyridines in methanol: synthesis and crystal structure of [Pd(terpy)(py)](ClO4)2. Inorg. Chim. Acta 2004, 357, 2650-2656; (b) Carta, V.; Mehr, S. H. M.; MacLachlan, M. J. Controlling Ligand Exchange through Macrocyclization. Inorg. Chem. 2018, 57, 32433253.

(44) Smulders, M. M. J.; Schenning, A. P. H. J.; Meijer, E. W. Insight into the Mechanisms of Cooperative Self-Assembly: The "Sergeants-andSoldiers" Principle of Chiral and Achiral C3-Symmetrical Discotic Triamides. J. Am. Chem. Soc. 2007, 130, 606-611. 


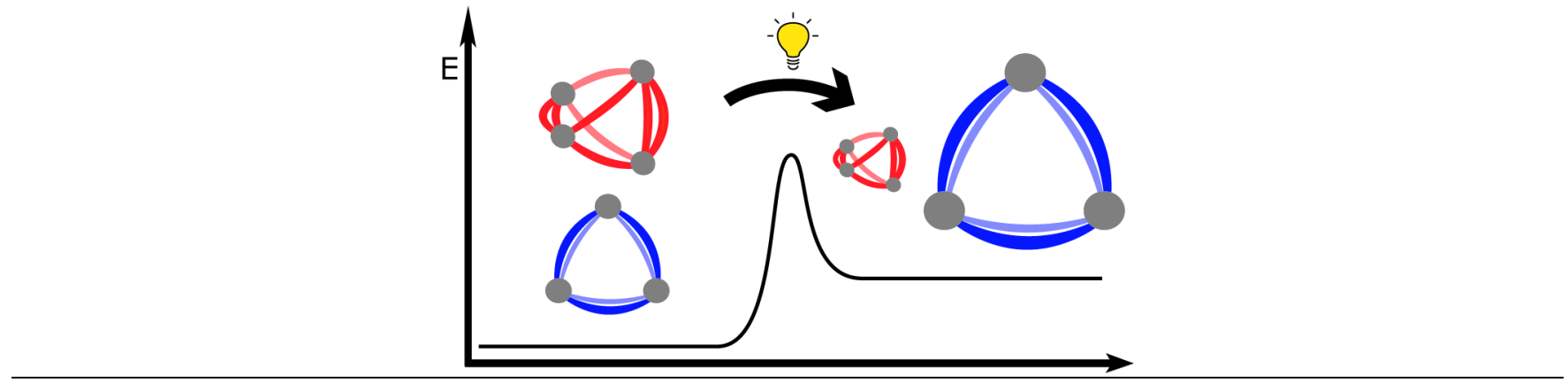

9 